\title{
Effects of Fluoride Release on Enamel Color Alteration
}

\author{
Mahmoud Nabil El-Saafin, \\ Firas Hadad, \\ Victor Suciu,
}

Medicine and Pharmacy, University of Tirgu Mures, Faculty of Dental Medicine, 38 Gheorghe Marinescu, Tirgu Mures, Romania.

Marioara Moldovan,

Babes Bolyai University of Cluj-Napoca, Department of Polymeric Composites, 1 Mihail Kogalniceanu, Cluj Napoca, Romania.

\section{Mariana Pacurar}

Medicine and Pharmacy, University of Tirgu Mures, Faculty of Dental Medicine, 38 Gheorghe Marinescu, Tirgu Mures, Romania.

doi: 10.19044/esj.2017.v13n24p462 URL:http://dx.doi.org/10.19044/esj.2017.v13n24p462

\begin{abstract}
The aim of this study is to evaluate teeth discoloration after the usage of adhesive fluoride release. Material and Method: 80 extracted healthy premolars divided into two groups were used in the study, with metal brackets being bonded in both groups,. The first group universal adhesive was applied (transbond light cure adhesive paste-Transbond XT), whereas in the second group fluoride releasing bonding material was used (opal bond MV composite and opal seal). The measurement of color parameters was performed using the spectrophotometer vita easyshade 4.0 to calculate $\Delta \mathrm{L}$, $\Delta \mathrm{a}, \Delta \mathrm{b}$, and $\Delta \mathrm{E}$. Statistical Analysis: 3-way mixed analysis of variances (ANOVA) was used to compare $\Delta \mathrm{E}$ before using adhesive material and after the procedure. On the other hand, it was used to compare $\Delta \mathrm{a}, \Delta \mathrm{b}$, and $\Delta \mathrm{L}$ before and after using adhesive material. The statistical significance level was established at $\mathrm{P}<0.05$. Boferroni correction was used to create mean differences between the results. Results: The result of this study showed that $\Delta \mathrm{E}^{*}$ values were increased in all groups. The mean difference of $\Delta \mathrm{E}^{*}$ value in the first group (3M adhesive material) was $2.54 \pm 1.57$. At the same time, the $\Delta \mathrm{E}$ value in opal adhesive group was $4.43 \pm 5.4$. These results showed that fluoride seal had direct effect on enamel color after a period of three months teeth storage. Results showed above the normal limit and produced visible color change on the surface of the teeth after finishing procedure. On the other hand, $\Delta \mathrm{L}$ values were increased in both groups, with a significant
\end{abstract}


difference in the first group ( $\mathrm{p}$ value 0.04 ) and with no significant difference in the second group ( $\mathrm{p}$ value 0.239 ). Conclusion: The highest color changes were observed after the finishing procedure in opal bond MV composites and the opal seal groups. This was done by increasing $\Delta \mathrm{E}$ value due to the presence of fluoride release adhesive structure. Transbond light cure adhesive past-Transbond XT had acceptable clinical change after the debonding and finishing procedure by increasing $\Delta \mathrm{E}$ value.

Keywords: Debonding, Teeth, Transbond Light Cure Adhesive PastTransbond XT, Fluoride, Adhesive

\section{Introduction}

Esthetic appearance of the oral cavity is one of the most important aims of orthodontic treatment. Several factors affect the natural color of the teeth, for example: the condition of the light coming from the surrounding environment, the color of gingival tissue and nature of the saliva that provides the tooth hydration, and the reflective index coming from the underlying surface (Goodkind \& Schwabacher, 1987; Dawes, 1974).

However, recent studies showed that bonding and debonding of brackets in orthodontic treatment may cause tooth discoloration (Eliades et al., 2001; Trakyali et al., 2009).

Remnant adhesive composite, surrounding the brackets bonded to the tooth or after debonding brackets, helped in the process of accumulation of the plaque of bacteria that may form whitish spots and periodontal problems (Bishara \& Trulove, 1990; Quirynen \& Bollen, 1995).

At the same time, cleaning up procedures and debonding brackets may cause micro cracks and fractures on the enamel surface that creates damage to the teeth (Pus \& Way, 1980; Diedrich, 1981; Sandisson, 1981; Eliades et al., 2001).

The Appearance of white spots lesion on the surfaces of the teeth during and after orthodontic treatment may be caused by hypomineralization of the enamel materials as in procedures of bonding and debonding of brackets. These white spots could cause a big change in the natural color of teeth (Sandison, 2016).

The storage of foods and drinks may also lead to the appearance of stains on the teeth by causing discolorations on the enamel surfaces.

To measure tooth color appearance, two common ways are described. The first method is by visual examination, and it is the most common method used in dentistry for color change examination (van der Burgt et al., 1990). Several factors may influence the matching of visual color examination like external room light, doctor's experience, age and the tiredness of the eyes (Billmeyer \& Saltzman, 1981; Preston, 1985; Rubino et al., 1994). 
The second method of tooth color examination was done through electronic optical sensors (Panariva, 2004). This method was more accurate than the visual method. Various common systems have been used in researches like tristimulus colorimeters, spectroradiometers, spectrophotometers and digital color analyzers (Joiner, 2004).

\section{Materials and Methods}

This study was conducted through eighty extracted teeth. The criteria for the selection of samples were teeth without restorations, attritions, and fractions. All teeth were stored in normal saline to protect them from dehydration and the saline was carefully changed weekly to prevent bacterial growth. All teeth were polished by pumice to clean all the enamel surfaces of the teeth.

\section{Materials Used}

The first material group chosen was 3M adhesive (Transbond Light cure Adhesive paste-Transbond XT) with unitek TM miniature twin metal brackets. For the second group, Opal adhesive (opal bond MV composite and opal seal) and avex brackets were chosen.

Acid Etched: Usage of (blue etch) acid etch with a concentration of 36\% phosphoric-acid for 20 seconds.

Bonded by Transbond XT Primer and Opal Seal: In each sub-group, after the etched area became frosty white, the enamel bonding agent (40 teeth were bonded with Transbond XT and 40 teeth were bonded with Opal Seal) was placed in a uniform thin coat using a special brush on the enamel surface and activated with LED light cure for 10 seconds. The enamel surface to be bonded had to appear shiny. Then a small quantity of the adhesive paste was placed on the base of the brackets which was fixed at a $4 \mathrm{~mm}$ distance from the occlusal plane on the teeth surface with a stable pressure. The excess material was eliminated by using a sharp probe without changing the position of the brackets. The adhesive-bracket-tooth interface was exposed to the light curing for 20 Seconds at a distance of $5 \mathrm{~mm}$.

The teeth were stored 3 months in artificial saliva at $37^{\circ} \mathrm{C}$.

\section{Debonding and Resin Removal}

The brackets were removed using debonding plier. In both groups, the remnant composites were removed with a blade tungsten carbide bur connected to low speed handpiece. 


\section{Measurement of the Color Parameters}

Measurement of the color parameters was performed using the Spectrophotometer Vita Easyshade 4.0.

The spectrophotometer was used for each tooth twice. The first time was before applying the adhesive material and bonding the brackets, while the second time was after finishing the procedure and removing the adhesive remnants.

The spectrophotometer consists of three main elements: a light source, a way to direct the light source to an object and to receive the light reflected by the object, and a spectrometer which determines the intensity of incoming light depending on the wavelength. As a result of own source of light, tooth color can be determined in any lighting condition. Measurements were performed globally with the aim to determine color parameters: $\mathrm{L}^{*}$ (brightness), a * (chromatic parameter in red-green axis), and $\mathrm{b} *$ (chromatic parameter in yellow-blue axis).

Measurements were taken before and after establishing the whitening protocol with experimental and commercial materials. The measurements were done at the surface of each tooth. For each area, three measurements were made and their average was calculated. However, this was used in calculating the difference in color using the formula below:

$$
\Delta E=\sqrt{\Delta L^{2}+\Delta a^{2}+\Delta b^{2}}
$$

Where L1 $*$ (Brightness), a1 $*$ (chromatic parameter in red-green axis), b1 * (chromatic parameter in yellow-blue axis) represent the chromatic parameters before applying the bracket (on the buccal surface). Also, L2 * (Brightness), a2 * (chromatic parameter in red-green axis), b2 * (chromatic parameter in yellow-blue axis) represent the chromatic parameters after finishing procedure protocol (on the buccal surface).

From a clinical point of view, according to the capacity of visual perception of people and the environment, some thresholds have been established. These thresholds include the threshold $50 / 50 \%$ of $\Delta \mathrm{E}_{\mathrm{ab}}=1.0$ perception and acceptability threshold $\Delta \mathrm{E}_{\mathrm{ab}}=3.7$. However, threshold 50/50\% of $\Delta \mathrm{E}_{\mathrm{ab}}=1.0$ perception means the limit above, $50 \%$ the observers perceive a difference in color and the other $50 \%$ do not. The acceptability threshold $\Delta \mathrm{E}_{\mathrm{ab}}=3.7$ is the extent to which patients will consider color difference to be clinically acceptable.

\section{Statistical Analysis}

SPSS (version 8.0) was used in this study to create statistical analysis and to compare the results. 3-way mixed analysis of variance (ANOVA) was used to compare mean $\Delta \mathrm{E}$ before using adhesive material and after finishing the procedure. Furthermore, it was also used to compare between $\Delta a, \Delta b$, 
and $\Delta \mathrm{L}$ before and after using adhesive material. The statistical significance level was established at $\mathrm{P}<0.05$.

Boferroni correction was used to create mean difference between the results.

\section{Results}

The results of this study CIE color parameters of all extracted teeth before bonding and after the finishing of the procedure. Table 1 shows numbers of teeth used in each group.

Table 1. The teeth number used in each group

\begin{tabular}{|ll|l|r|}
\hline & & Value Label & $\mathrm{N}$ \\
\hline Groups & 1.00 & Control & \\
& 2.00 & Opal seal & 80 \\
& 3.00 & $3 \mathrm{M}$ & 40 \\
&
\end{tabular}

In Table 2, the result of the 3-way ANOVA showed thattime had a significant effect for color parameters. Thus, the parameters of $a, L, b$, and $E$ were significant with adhesive material.

Table 2. 3-way mixed analysis of variance (ANOVA) for color parameters with respect to the effect of time and adhesive materials

\begin{tabular}{|c|c|c|c|c|c|c|}
\hline Source & Dependent Variable & $\begin{array}{l}\text { Type III Sum } \\
\text { of } \\
\text { Squares }\end{array}$ & df & $\begin{array}{l}\text { Mean } \\
\text { Square }\end{array}$ & $\mathrm{F}$ & Sig. \\
\hline \multirow{4}{*}{$\begin{array}{l}\text { Corrected } \\
\text { Model }\end{array}$} & \multirow{4}{*}{$\begin{array}{l}\mathrm{L} \\
\mathrm{a} \\
\mathrm{b} \\
\mathrm{E}\end{array}$} & $42.249^{\mathrm{a}}$ & 2 & \multirow{4}{*}{$\begin{array}{r}21.124 \\
26.116 \\
116.633 \\
198.248\end{array}$} & 3.331 & \multirow{4}{*}{$\begin{array}{l}.039 \\
.000 \\
.000 \\
.000\end{array}$} \\
\hline & & $52.233^{\mathrm{b}}$ & 2 & & 18.713 & \\
\hline & & $233.267^{\mathrm{c}}$ & 2 & & 15.778 & \\
\hline & & $396.496^{d}$ & 2 & & 18.172 & \\
\hline \multirow[t]{4}{*}{ Intercept } & \multirow{4}{*}{$\begin{array}{l}\mathrm{L} \\
\mathrm{a} \\
\mathrm{b} \\
\mathrm{E}\end{array}$} & 695645.496 & 1 & 695645.496 & 109705.665 & .000 \\
\hline & & 3698.964 & 1 & 3698.964 & 2650.425 & .000 \\
\hline & & 48884.033 & 1 & 48884.033 & 6612.824 & .000 \\
\hline & & 1723.086 & 1 & 1723.086 & 157.944 & .000 \\
\hline \multirow[t]{4}{*}{ Groups } & \multirow{4}{*}{$\begin{array}{l}\mathrm{L} \\
\mathrm{a} \\
\mathrm{b} \\
\mathrm{E}\end{array}$} & \multirow{4}{*}{$\begin{array}{r}42.249 \\
52.233 \\
233.267 \\
396.496\end{array}$} & 2 & \multirow{4}{*}{$\begin{array}{r}21.124 \\
26.116 \\
116.633 \\
198.248\end{array}$} & 3.331 & .039 \\
\hline & & & 2 & & 18.713 & .000 \\
\hline & & & 2 & & 15.778 & .000 \\
\hline & & & 2 & & 18.172 & .000 \\
\hline \multirow[t]{4}{*}{ Error } & $\mathrm{L}$ & 741.899 & 117 & 6.341 & & \\
\hline & $\mathrm{a}$ & 163.287 & 117 & 1.396 & & \\
\hline & $b$ & 864.900 & 117 & 7.392 & & \\
\hline & $\mathrm{E}$ & 1276.410 & 117 & 10.909 & & \\
\hline
\end{tabular}




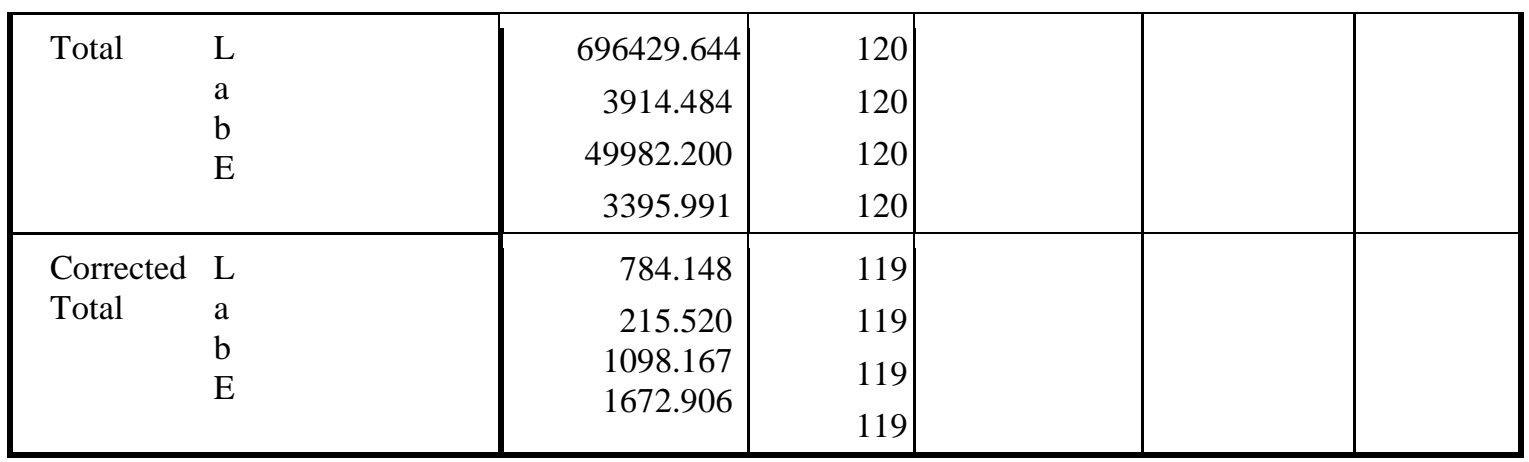

a. $\mathrm{R}$ Squared $=.054$ (Adjusted R Squared $=.038), \mathrm{b} . \mathrm{R}$ Squared $=.242$ (Adjusted R Squared $=.229$ )

c. R Squared $=.212($ Adjusted R Squared $=.199)$, d. R Squared $=.237$ (Adjusted R Squared $=.224$ )

In Table 3, $\Delta \mathrm{E}$ value increased after debonding and after finishing the procedure for all groups. The mean difference of $\Delta \mathrm{E}$ value in $3 \mathrm{M}$ adhesive group before and after (debonding and finishing procedure) was 2.54 \pm 1.57 with significant difference ( $p$ value 0.034). At the same time, the mean difference of $E$ value in opal adhesive group was $4.43 \pm 5.4$ with a significant difference ( $\mathrm{p}$ value 0.001$)$.

The mean difference of $\Delta \mathrm{L}$ value in the first group and the second group increased by $1.415 \pm 1.62$ and $0.995 \pm 3.45$ with significant difference in the first group ( $\mathrm{p}$ value 0.04 ) and no significant difference in the second group ( $\mathrm{p}$ value 0.239 ).

The mean difference of $\Delta \mathrm{a}$ value decreased in the first and second groups ( $\Delta \mathrm{a}$ in the first group $-1.55 \pm 0.7$ and in the second group -1.15 \pm 1.54 ). In both groups, there were significant differences $(0.001$ and 0.001$)$.

Thus, the first group's results show increase in the mean difference of $\Delta b$ value with $2.25 \pm 2.17$. These results were in contradiction with the second group because $\Delta b$ value decreased with $-1.1 \pm 3.24$. Also, both groups had significant differences in the first and second group ( $\mathrm{p}$ value 0.34 and $\mathrm{p}$ value 0.001).

Table 3. Mean \pm SD values of all measured teeth before and after finishing the procedure

\begin{tabular}{|c|c|c|c|c|c|c|}
\hline \multirow[b]{2}{*}{$\begin{array}{l}\text { Dependent } \\
\text { Variable }\end{array}$} & \multirow[b]{2}{*}{ Group } & \multirow[b]{2}{*}{$\begin{array}{l}\text { Mean } \pm \\
\text { SD }\end{array}$} & \multirow[b]{2}{*}{$\begin{array}{l}\text { Std. } \\
\text { Error }\end{array}$} & \multirow[b]{2}{*}{$P$ value } & \multicolumn{2}{|c|}{ 95\% Confidence Interval } \\
\hline & & & & & $\begin{array}{l}\text { Lower } \\
\text { Bound }\end{array}$ & $\begin{array}{l}\text { Upper } \\
\text { Bound }\end{array}$ \\
\hline t & $\begin{array}{l}\text { Group2 } \\
\text { Opal }\end{array}$ & $0.99 \pm 3.45$ & 0.56307 & 0.239 & -.3726 & 2.3626 \\
\hline
\end{tabular}




\begin{tabular}{|c|c|c|c|c|c|c|}
\hline & $\begin{array}{l}\text { Group1 } \\
3 \mathrm{M}\end{array}$ & $1.41 \pm 1.62$ & 0.56307 & 0.040 & 0.0474 & 2.7826 \\
\hline \multirow{2}{*}{$\mathrm{A}$} & $\begin{array}{l}\text { Group2 } \\
\text { Opal }\end{array}$ & $-1.15 \pm 1.54$ & 0.26416 & 0.001 & -1.7976 & $\begin{array}{l}- \\
0.5144\end{array}$ \\
\hline & $\begin{array}{l}\text { Group1 } \\
3 \mathrm{M}\end{array}$ & $-1.55 \pm 0.70$ & 0.26416 & 0.001 & -2.1976 & -0.9144 \\
\hline \multirow{2}{*}{ B } & $\begin{array}{l}\text { Group2 } \\
\text { Opal }\end{array}$ & $-1.1 \pm 3.24$ & 0.60796 & 0.219 & -2.5767 & 0.3767 \\
\hline & $\begin{array}{l}\text { Group1 } \\
3 \mathrm{M}\end{array}$ & $2.25 \pm 2.17$ & 0.60796 & 0.001 & 0.7733 & 3.7267 \\
\hline \multirow{2}{*}{$\mathrm{E}$} & $\begin{array}{l}\text { Group2 } \\
\text { Opal }\end{array}$ & $4.43 \pm 5.40$ & 0.73856 & 0.001 & 2.6431 & 6.2309 \\
\hline & $\begin{array}{l}\text { Group1 } \\
3 \mathrm{M}\end{array}$ & $1.89 \pm 1.57$ & 0.73856 & 0.034 & .1031 & 3.6909 \\
\hline
\end{tabular}

\section{Discussion}

The esthetic consideration was the first goal for most of the patients that needed orthodontic treatment. Therefore, the teeth discoloration during and after orthodontic treatment was an important challenge for all orthodontist.

Several etiological factors affected optical characteristics of the enamel surface during orthodontic treatment. For example, using phosphoric acid etching increased the microscopic roughness of the enamel surface leading to enamel discoloration and loss of about $10-20 \mu \mathrm{m}$ by dissolution of apatite crystallites (Eliades et al., 2001; Silverstone, 1985). On the other hand, debonding brackets and removing remnant adhesive material could affect external tooth morphology and reform texture modification. This also has a significant effect on the natural tooth color (A). As a result, the use of tungsten carbide bur to minimize enamel damage during the removal of adhesive remnants was recommended (Trakyali et al., 2009; Joiner, 2004; Pus \& Way, 1980; Zachrisson \& Artun, 1979). 
On the other hand, individual facial characteristics affected tooth color appearance such as age, sex, skin color, lips, and color of the gums (Alkhatib, 2005).

The dental material structure affected the smoothness of the enamel surface and could lead to the discoloration of the teeth.

Two factors could affect the color change of polymers: the external factors such as enamel absorption of diet color pigmentation and superficial absorption, and the internal factor like chemical structure (da Costa et al., 2010; Corekci et al., 2010; Trakyali et al., 2009; Dietschi et al., 1994; Lazzetti et al., 2000; Leibrock et al., 1997).

The major reasons for using fluoride release in adhesive orthodontic material was to inhibit decalcification during the treatment, white spots around the brackets and antibactericidal effect. At the same time, the fluoride releasing material had positive effect on the hardness and elastic modulus of enamel (Seyed Hamid Raji et al., 2014).

On the other hand, Eser T. and Daniel R. observed that using fluoride releasing materials did not reduce demineralization or white spots during orthodontic treatment (Eser Tufekc€ et al., 2014).

Therefore, the mean objective of this study was to evaluate teeth discoloration after using fluoride releasing adhesive on 40 extracted teeth and to measure teeth color changes after three months of storage in artificial saliva at $37^{\circ} \mathrm{C}$. Also, it compares the results with other universal adhesive material.

Increasing bonding strength was the reason behind choosing the same manufacturer company of adhesive material and brackets to avoid any statistical error (Elsaafin Mahmoud et al., 2017). Teeth discoloration in human life is generally more possible with external factors, for example smoking and drinking coffee. With the addition of orthodontic treatment, the rate of tooth discoloration will increase.

$\mathrm{L}$ value referred to the degree of lightness in the munsel system, and the value of $\mathrm{L}$ between 0 (black) and 100 (white). So the acceptable level of $\Delta \mathrm{L}$ value was set at 2.0 unit because if $\Delta \mathrm{L}$ will increase more than 2.0 unit, the humane eye can observe that change (Chung, 1994).

a value is the measurement of redness (a value more than 0 ) or greenness (a value less than 0 ), while $b$ value is important to calculate the rate of yellowness $(b>0)$ or blueness $(b<0)$.

The acceptable level of $\Delta \mathrm{E}$ value was set between 1 to 3.7 unit(Agoston et al., 1979; Johnston \& Kao, 1989).

Bonding materials have direct effect on tooth discoloration and $\Delta \mathrm{E}$ between 0.85 to 1.51 units (Trakyali et al., 2009).

This study showed that $\Delta \mathrm{E}$ values increased in all groups and the mean difference of $\Delta \mathrm{E}$ values in first group (3M adhesive material) $2.54 \pm$ 
1.57 with a significant difference ( $\mathrm{p}$ value 0.034). This difference was acceptable and did not show visual difference in the result. At the same time, the $\Delta \mathrm{E}$ value in opal adhesive group was $4.43 \pm 5.4$ with significant difference ( $\mathrm{p}$ value 0.001 ). This result showed that fluoride seal had direct effect on enamel color after three month of teeth storage. Results were above the value limit and produced color changes on the surface of the teeth after finishing procedure.

On the other hand, $\Delta \mathrm{L}$ values increased in both groups with a significant difference in the first group ( $\mathrm{p}$ value 0.04 ) and with no significant difference in the second group ( $\mathrm{p}$ value 0.239 ).

\section{Conclusion}

- The adhesive material has a direct effect on tooth discoloration.

- The highest color change was observed after the finishing procedure in opal bond $\mathrm{MV}$ composite and opal seal group by increasing $\Delta \mathrm{E}$ value caused by having fluoride relies adhesive structure.

- Transbond light cure adhesive paste-Transbond XT had acceptable clinical change after debonding and finishing procedure by increasing $\Delta \mathrm{E}$ value.

- All groups showed significant difference before and after the finishing of the procedure in $\Delta \mathrm{E}, \Delta \mathrm{L}, \Delta \mathrm{a}$, and $\Delta \mathrm{b}$ except opal seal group which had no significant difference in $\Delta \mathrm{L}$ and $\Delta \mathrm{b}$.

\section{References:}

1. Agoston, GA. (1979). Color theory and its application in art and design. Heidelberg: Springer-Verlag; 137.

2. Alkhatib, MN., Holt, R., \& Bedi, R. (2005). Age and perception of dental appearance and tooth color. Gerontology; 22:32-6.

3. Billmeyer, FW \& Saltzman, M. (1981). Principles of color technology. $2^{\text {nd }}$ ed. New York: John Wiley and Sons; p. 1-110.

4. Bishara, SE. \& Trulove, TS. (1990). Comparisons of different debonding techniques for ceramic brackets: an in vitro study. Part II. Findings and clinical implications. Am J Orthod Dentofacial Orthop; 98:263-273. [Crossref] [Medline].

5. Chung, KH. (1994). Effects of finishing and polishing procedures on the surface texture of resin composites. Dent Mater 1994; 10: 325330.

6. Corekci, B., Irgin, C., Malkoc, S. \& Ozturk, B. (2010). Effects of staining solutions on the discoloration of orthodontic adhesives: an in-vitro study. Am J Orthod Dentofacial Orthop 2010; 138: 741-746. 
7. da Costa, J., Fox, P., \& Ferracane, J. (2010). Comparison of various resincomposite shades and layering technique with a shade guide. $\mathrm{J}$ Esthet Restor Dent; 22: 114-124.

8. Dawes, C. (1974). Rhythms in salivary flow rate and composition. Int J Chronobiol; 2:253-79.

9. Diedrich, P. (1981). Enamel alteration from bracket bonding and debonding: a study with the scanning electron microscope, American Journal of Orthodontics, vol. 79 (pg. 500-522).

10. Dietschi, D., Campanile, G., Holz, J., \& Meyer, JM. (1994). Comparison of the color stability of ten new generation composites: an in vitro study. Dent Mater 1994; 10: 353-362.

11. Eliades, T., Kakaboura, A., Eliades, G. \& Bradley, TG. (2001). Comparison of enamel colour changes associated with orthodontic bonding using two different adhesives. Eur J Orthod; 23:85-90.

12. Elsaafin Mahmoud, Mariana Pacurar, Edwin Sever Bechir1, Marius Maris, Christian Olteanu, Ionela Teodora Dascalu, \& Marioara Moldovan (2017). Comparison of Shear Bond Strength and Adhesive Remnant Index of Brackets Bonded with Two Types of Orthodontic Adhesives. MATERIALE PLASTICE. 54, No.1, 2017. 141:144.

13. Eser Tufekc€,I., Daniel, R., Pennella, John C. Mitchell, Al M. Best, Steven J. Lindauer Richmond, Va, Lexington, SC., and Glendale Ariz (2014). Efficacy of a fluoride-releasing orthodontic primer in reducing demineralization around brackets: An in-vivo study. Am J Orthod Dentofacial Orthop; 146:207-14.

14. Goodkind, RJ \& Schwabacher, WB (1987). Use of a fiber-optic colorimeter for in vivo color measurements of 2830 anterior teeth. J Prosthet Dent 1987; 58:535-42.

15. Iazzetti, G., Burgess, JO., Gardiner, D., \& Ripps, A. (2000). Color stability of fluoride-containing restorative materials. Oper Dent; 25: 520-525.

16. Leibrock, A., Rosentritt, M., Lang, R., Behr, M. \& Handel G. (1997). Colour stability of visible light-curing hybrid composites. Eur J Prosthodont Restor Dent 1997; 5: 125-130.

17. Jahanbin, A., Ameri, H. \& Khaleghimoghaddam, R. (2009). Effect of adhesive types on enamel discolouration around orthodontic brackets, Australian Orthodontic Journal, vol. 25, no. 1, pp. 1923. View at Google Scholar. View at Scopus.

18. Joiner, A. (2004). Tooth colour: A review of the literature. J Dent; 32(Suppl 1):3-12.

19. Johnston W.M. \& Kao, E. C. (1989). Assessment of appearance match by visual observation and clinical colorimetry, Journal of Dental Research, vol. 68, no. 5, pp. 819-822, 1989. 
20. Karan, S., Kircelli, BH. \& Tasdelen, B. (2010). Enamel surface roughness after debonding. Angle Orthod;80:1081- 1088.

21. Panariva, RD. \& Powers, JM. (2004). Esthetic color training in dentistry. 1st ed. Edinburgh, United Kingdom: Elsevier-Mosby. p. 165-72.

22. Preston, JD. (1985). Current status of shade selection and color matching. Quintessence Int;1:47-58.

23. Pus, MD \& Way, DC. (1980). Enamel loss due to orthodontic bonding with filled and unfilled resins using various clean-up techniques American Journal of Orthodontics and Dentofacial Orthopedics, vol. 77 (pg. 269-283).

24. Quirynen, M. \& Bollen, CML. (1995). The influence of surface roughness and surface-free energy on supra- and subgingival plaque formation in man. A Review of the literature. J Clin Periodontol; 22:1-14. [Crossref] [Medline].

25. Rubino, M., Barcia, JA., Jimenez del Barco, L., \& Romero, J. (1994). Color measurement of human teeth and evaluation of a color guide. Color Res Appl;19:19-22.

26. Sandisson, R. (1981). Tooth surface appearance after debonding, British Journal of Orthodontics, vol. 8 (pg. 199-201).

27. Sandison, R. M., B.D.S., F.D.S. (2016). D.Ortho.R.C.S Tooth Surface Appearance After Debonding. Pages 199-201 | Published online: 21 Jun 2016.

28. Seyed Hamid Raji, Hamed Banimostafaee, \& Fatemeh Hajizadeh (2014). Effects of fluoride release from orthodontic bonding materials on nanomechanical properties of the enamel around orthodontic brackets. Dent Res J (Isfahan). 2014 Jan-Feb; 11(1): 6773.

29. Silverstone, LM., Saxton, CA., Dogon, IL. \& Fejerskov, O. (1975). Variation in the pattern of acid etching of human dental enamel examined by scanning electron microscopy. Caries Res; 9: 373-387.

30. Trakyali, G., Ozdemir, FI. \& Arun, T. (2009). Enamel colour changes at debonding and after finishing procedures using five different adhesives. Eur J Orthod;31:397-401.

31. van der Burgt, TP., ten Bosch, JJ., Borsboom, PC., \& Kortsmit, WJ. (1990). A comparison of new and conventional methods for quantification of tooth color. J Prosthet Dent; 63:155-62.

32. Zachrisson, BU. \& Artun, J. (1979). Enamel surface appearance after various debonding techniques. Am J Orthod; 75: 121-137. 